\title{
Tussen Heumensoord en Winschoten
}

\section{Over de tegenstrijdige betekenis van burgerparticipatie in de veiligheidszorg}

\section{J. Terpstra*}

Als antwoord op de enorme stroom vluchtelingen naar West-Europa vanuit Syrië en andere landen met oorlog, honger en andere mensonterende ellende wordt in september 2015 in de bossen van Heumensoord bij Nijmegen een tijdelijke opvang uit de grond gestampt voor asielzoekers. Dit tentenkamp biedt de mogelijkheid ongeveer drieduizend personen onder te brengen in afwachting van een meer permanente verblijfsplaats. In een verscheurd maatschappelijk en politiek klimaat over de vraag hoe om te gaan met deze toestroom van vreemdelingen besluit een groot aantal burgers uit Nijmegen en omgeving zich aan te melden om als vrijwilliger te helpen de vaak gebrekkige omstandigheden en opvang in het kamp nog enigszins acceptabel te maken. Burgers melden zich aan voor uiteenlopende activiteiten en klusjes als eten opscheppen, kinderopvang en als voetbalcoach of om mensen te helpen met uiteenlopende praktische vragen en problemen. De spontane inzet van zovelen is indrukwekkend. De massale omvang van de stroom van mensen die hulp en steun willen bieden, maakt dat de partijen die verantwoordelijk zijn voor de organisatie en inzet van vrijwilligers in het kamp op een gegeven moment niet meer goed weten wat ze met de grote aantallen goedbedoelende mensen aan moeten.

In totaal zijn ruim drieduizend vrijwilligers in en rond het kamp Heumensoord actief geweest in de ruim zeven maanden dat het heeft bestaan. Velen hebben het gevoel dat de hartverwarmende bijdrage van deze burgers veel verder reikt dan het alleen maar in de bossen van Nijmegen uitdelen van soep en het bij een zandbak zitten (hoe

* Prof. dr. ir. Jan Terpstra is als hoogleraar criminologie verbonden aan de faculteit der rechtsgeleerdheid van de Radboud Universiteit te Nijmegen. 
belangrijk dat overigens ook is). Uitdrukking aan dat gevoel geeft burgemeester $\mathrm{H}$. Bruls van de gemeente Nijmegen op een bijeenkomst op 25 mei 2016, die wordt georganiseerd ter gelegenheid van de sluiting van het kamp. Hierbij worden ook de vele vrijwilligers van Heumensoord bedankt voor hun inzet. Bruls merkt op, verwijzend naar deze massale inzet: 'Nederland is niet alleen een land van polarisatie, maar Nederland, dat is Heumensoord.' ${ }^{1}$

Participatie van burgers in de veiligheidszorg in Nederland in deze periode kent ook een ander gezicht. Twee maanden na de optimistische woorden van de Nijmeegse burgemeester, in juli 2016, doet zich een incident voor in de gemeente Winschoten. Verschillende massamedia melden dat in die plaats een groep die zich de Soldiers of Odin noemt een jonge mannelijke asielzoeker zou hebben aangehouden en aan de politie hebben overgedragen omdat hij verschillende vrouwen zou hebben lastiggevallen. Volgens de Volkskrant zou er een 'klopjacht' op de jongeman hebben plaatsgevonden die een uur zou hebben geduurd. Op het moment dat de politie de asielzoeker aantreft, blijkt hij mishandeld te zijn. De politie ontkent overigens dat de jongeman aan haar zou zijn overgedragen door leden van deze groep. ${ }^{2}$ De Soldiers of Odin is in 2015 ontstaan in Finland in reactie op de toestroom van migranten. Zij is in korte tijd overgewaaid naar andere landen, waaronder Nederland. In ons land zou zij volgens eigen zeggen beschikken over inmiddels zeven 'chapters'. De organisatie omschrijft zichzelf als straatpatrouilleclub die wil strijden tegen 'criminelen': 'Protecting our citizens and defending our streets'. De organisatie ontleent haar naam en de door haar gebruikte symbolen op haar kleding en Facebookpagina aan oude Noorse mythologieën. In groepen op straat zijn de leden herkenbaar aan hun geschoren koppen, camouflagebroeken en donkere jasjes of truien met achterop de naam Soldiers of Odin erop. Een van de motto's waaronder de organisatie in Nederland opereert, is: 'Dit is Nederland. We eten varkensvlees. Drinken bier. En spreken Nederlands. ${ }^{3}$ Volgens de 'onderzoeksgroep' Kafka zou het hier gaan om een rechtsextremistische groepering. ${ }^{4}$

1 Zie www.coa.nl/actueel/nieuws/warm-afscheid-van-heumensoord, geraadpleegd op 14 september 2016.

2 Zie de Volkskrant 19 juli 2016.

3 Zie www.facebook.com/Soldiers-Of-Odin-Netherlands-support-693269787476451, geraadpleegd op 15 september 2016.

4 Zie Algemeen Dagblad 19 juli 2016. 
Deze twee voorbeelden van burgerparticipatie in de veiligheidszorg zijn hier om twee redenen opgevoerd. Ten eerste, onder de noemer van burgerparticipatie in de veiligheidszorg worden vaak zeer uiteenlopende verschijnselen geplaatst, die op vele punten niet of nauwelijks met elkaar te vergelijken zijn. De termen burgerparticipatie en veiligheidszorg suggereren een eenheid waarvan slechts in beperkte mate sprake is. Het is dan ook belangrijk deze diversiteit en de daarmee verbonden verschillen in context en betekenis in het oog te houden. Ten tweede, en nauw hiermee verbonden, valt veel van deze burgerparticipatie niet te begrijpen vanuit alleen een instrumenteel perspectief. Dit veelal impliciete perspectief domineert echter vaak in de literatuur over burgerparticipatie in de veiligheidszorg. Burgerparticipatie is echter veel meer dan slechts een 'instrument'. Dit perspectief is ook terug te vinden in verschillende bijdragen aan dit nummer van Justitiele verkenningen.

In tijden van populisme en van maatschappelijke polarisatie wordt, juist rond veiligheidsvraagstukken, duidelijk hoezeer een dergelijke instrumentalistische invalshoek tekortschiet. Juist onder dergelijke omstandigheden treden deze diversiteit en daarmee verbonden tegenstellingen, spanning en conflicten rond burgerparticipatie in de veiligheidszorg sterk naar voren. Het is dit thema dat in dit artikel centraal staat, waarin ik op verzoek van de redactie van Justitiële verkenningen reageer op de verschillende bijdragen aan dit nummer.

\section{Burgerparticipatie en het doel van criminaliteitsreductie}

Het instrumentalistische perspectief op burgerparticipatie in de veiligheidszorg kan worden duidelijk gemaakt aan de hand van een bekend artikel van Bennett, Holloway \& Farrington uit 2006, dat ook door verschillende auteurs in dit nummer van Justitiële verkenningen wordt aangehaald. In dit artikel wordt verslag gedaan van een meta-analyse van de op dat moment beschikbare evaluatieonderzoeken naar een bekende vorm van burgerparticipatie rond veiligheidsvraagstukken, namelijk de buurtwacht. Zonder enige nadere reflectie wordt er in deze analyse niet alleen van uitgegaan dat het centrale doel van deze burgergroepen bestaat uit vermindering van de criminaliteit, maar ook dat deze burgerinitiatieven onderling vergelijkbaar zijn. Elke informatie over wat voor groepen deze buurtwachten vormen en van- 
uit welke waarden, doelen of wel perspectief zij dit doen, ontbreekt in het artikel. Onduidelijk blijft daarmee of hier niet een met de Soldiers of Odin vergelijkbaar paramilitair initiatief op één hoop wordt gegooid met een groepje brave huisvaders die bij het uitlaten van hun hondje's avonds nog eens goed rondkijken of in hun woonwijk alles nog op orde is.

Met hun analyse proberen de auteurs na te gaan of de eerdere conclusie van Sherman e.a. (1997) standhoudt, namelijk dat de buurtwacht een ineffectief instrument is om de criminaliteit te verminderen. In tegenstelling tot Sherman e.a. concluderen Bennett e.a. dat buurtwachten wel degelijk een bijdrage kunnen leveren aan de vermindering van criminaliteit. Jammer is dat deze analyse geen enkel inzicht biedt in de vraag welke mechanismen in welke context dit effect zouden moeten verklaren, een constatering die overigens aansluit bij een eerdere kritiek van Pawson en Tilley (1997) op de werkwijze van Bennett in evaluatieonderzoek.

Burgerparticipatie in de veiligheidszorg kan echter niet goed worden begrepen als zij alleen in deze instrumentele termen wordt benaderd. De twee hiervoor gegeven voorbeelden (de massale opkomst van vrijwilligers in Heumensoord en de straatpatrouilles van de Soldiers of Odin) maken dat duidelijk. Hoewel beide verschijnselen kunnen worden beschouwd als vormen van burgerparticipatie in de veiligheidszorg, spelen in hun maatschappelijke betekenis veel meer elementen een rol dan alleen hun mogelijke bijdrage aan de reductie van criminaliteit. Door alleen naar deze instrumentele functie te kijken wordt een belangrijk element van de burgerbetrokkenheid gemist, zeker in de huidige omstandigheden.

\section{Harmonie en consensus in de veiligheidszorg}

Hierbij aansluitend is een tweede constatering van belang, namelijk dat het verschijnsel burgerparticipatie in de zorg voor veiligheid breder moet worden opgevat dan vaak gebruikelijk is. Het gaat hierbij niet alleen om die activiteiten die 'netjes' zijn, doelgericht of zich goed laten inpassen in het perspectief van instellingen als politie of gemeente. Burgerparticipatie in de veiligheidszorg is meer dan de vaak door formele instanties in de veiligheidszorg geïnitieerde of gesteunde activiteiten als Burgernet of buurtwacht. Deze passen bij de rationali- 
teit en verwachtingen van politie en justitie. Daarom wordt er dan ook gesproken van burgers als de 'ogen en oren' van politie en gemeente. Niet alle activiteiten van burgers laten zich echter op deze wijze instrumentaliseren.

Om die reden ook schiet de door Boutellier (2007) geïntroduceerde metafoor van de veiligheidszorg als voetbalteam tekort. Hierbij wordt verondersteld dat participerende burgers in de voorhoede van het veiligheidsteam worden opgesteld en gecoacht door de officier van justitie. In deze visie houdt deze als doelman niet alleen de tegengoals tegen, maar bepaalt hij ook de grote lijnen in het spel van zijn team en geeft hij aanwijzingen aan zijn medespelers, onder wie burgers. Verondersteld wordt ook dat burgers zich hierbij aan de regels houden van het spel bepaald door de overheid. In de praktijk zijn burgers echter ook bij de veiligheidszorg betrokken terwijl ze zich vooral door hun frustraties laten leiden, hun emoties de overhand hebben, ze alleen geïnteresseerd zijn in hun eigenbelang, hun kont tegen de krib willen gooien of simpelweg ‘tegen' zijn. Om in termen van de voetbalmetafoor te blijven: er is ook sprake van burgerparticipatie als burgers boos het veld aflopen, met een gestrekt been inkomen, of de scheidrechter lastigvallen. Om die reden vallen ook verschijnselen als stille marsen, protesten, Soldiers of Odin en rijke bewoners die hun eigen gated community opzetten wel degelijk onder burgerparticipatie (zie Terpstra 2010, p. 80-82). Dat is vast niet altijd leuk, laat zich lang niet altijd coachen door politie en justitie en is soms ook ronduit onacceptabel. Maar voor een goed begrip van burgerparticipatie in de veiligheidszorg moet de aandacht zich ook daarop richten.

Burgerparticipatie in de 'echte' werkelijkheid laat zich in toenemende mate niet meer goed scheiden van allerlei uitingen van onvrede van burgers op de sociale media. Scheldpartijen, pogingen mensen in een kwaad daglicht te stellen en oproepen om de ander die kwaad zou doen, eens de les te leren of daarop wraak te nemen, in eerste instantie beperkt tot de sociale media, lijken steeds meer een vervolg te krijgen in directe actie. De voorbeelden hiervan onlangs geschetst in de Volkskrant varieerden van 'uitzwaaidagen' en een oproep om 'ratten te vangen' in de Zaandamse wijk Poelenburg, waar een groep jongeren zich schuldig maakte aan ernstige overlast en het treiteren van politiemensen, tot een melding op Facebook van een groep die zich Kameraad- 
schap Noord-Nederland noemt, om in Oude Pekela in verzet te komen tegen de aanwezigheid van asielzoekers. ${ }^{5}$

Waarom is dit instrumentele perspectief zo overheersend in de wetenschappelijke literatuur over burgerparticipatie in de veiligheidszorg? Twee elementen lijken daarbij van belang. Ten eerste, wetenschappelijk onderzoekers lijken zich vaak te identificeren met het perspectief van instellingen als gemeente of politie. Dan komen zij bij hun zoektocht naar burgerparticipatie vooral uit bij burgers die zich hebben opgegeven voor Burgernet of bij de leden van een respectabele buurtwacht die samenwerkt met een wijkagent. Ze komen dan veel minder uit bij de anonieme klagers die hun vuil spuien via internet of bij de Soldiers of Odin. In de huidige situatie met vele verontwaardigde en boze burgers die geen blad voor hun mond menen te moeten nemen, met populisme en polarisatie tussen bevolkingsgroepen vooral rond veiligheid en criminaliteit wordt dan echter veel gemist van wat ook burgerparticipatie in de veiligheidszorg is.

Een tweede factor die hier mogelijk een rol speelt, is dat in veel analyses van veiligheidszorg, ondanks de soms postmoderne nadruk op fluïditeit, fragmentatie, multiple centres of governance en een wereld vol nodes, er uiteindelijk en ten onrechte van uit wordt gegaan dat er harmonie en orde heersen (zie voor deze constatering eerder ook De Haan 1995). De hang naar morele consensus lijkt het hier soms te winnen van het nuchtere inzicht dat harmonie en consensus rond veiligheidszorg juist vaak ver te zoeken zijn.

Voor het begrijpen van het functioneren van veiligheidszorg is het nodig meer uit te gaan van een conflictperspectief. Pogingen om veiligheid te bevorderen of te beschermen zijn in de regel onlosmakelijk verbonden met verschillen in visie, belangentegenstellingen en conflicten. Dat is ook zichtbaar bij de burgerparticipatie op dit terrein. Vaak gaat het simpelweg om de ruimte en erkenning van de ene groep tegenover de andere. Burgers die zich inzetten voor de verkeersveiligheid rond hun buurtschool beroepen zich uiteraard op het algemeen belang en de veiligheid van het kind, maar hoe dan ook staan zij daarmee op gespannen voet met de talloze automobilisten die toevallig geen schoolgaande kinderen hebben en het nut niet willen inzien van omleidingen en verkeersbelemmerende maatregelen. De pogingen om jeugdoverlast in een woonwijk tegen te gaan zijn vaak direct ver- 
bonden met de strijd tussen verschillende groepen over het gebruik van de openbare ruimte en de regels die daar gelden.

Het gaat daarmee bij burgerparticipatie om verschillen in perspectieven, probleemdefinities, waarden en belangen. De uitkomst van deze conflicten hangt mede samen met de verdeling van middelen om macht en invloed uit te oefenen en van de daarbij door verschillende partijen ingezette strategieën. Voor het begrijpen en waarderen van burgerparticipatie in de veiligheidszorg is het van het grootste belang deze onderliggende tegenstellingen en conflicten tot uitgangspunt te nemen en niet (impliciet) uit te gaan van harmonie en consensus. Met de fixatie op de schijnbaar eenduidige, instrumentele functie van burgerparticipatie en de beperking tot alleen die vormen van burgerparticipatie die in het straatje van de overheid passen, ontstaat een beperkt en vermoedelijk in veel gevallen te rooskleurig beeld van burgerparticipatie.

\section{Participatiemaatschappij}

Burgerparticipatie in de veiligheidszorg is inmiddels de onschuld voorbij. Dat is misschien een pijnlijke, maar ook onvermijdelijke conclusie. Verschillende vormen van burgerparticipatie kunnen wel de wens tot vermindering van criminaliteit als doel gemeen hebben, maar veel belangrijker is dat zij in hun symbolische uitstraling en onderliggende waarden zozeer van elkaar verschillen dat het hier in feite om conflicterende verschijnselen gaat. Daarmee verliezen ze in belangrijke mate hun vergelijkbaarheid. De term burgerparticipatie dreigt daarmee ook veel van haar betekenis te verliezen.

Tekenend voor de wijze waarop sommige onderzoekers de burgerparticipatie in de veiligheidszorg interpreteren en waarderen, is het gemak waarmee zij (ook in dit nummer van Justitiële verkenningen) de term participatiemaatschappij gebruiken, alsof dat een neutrale en feitelijke weergave is van onze huidige maatschappelijke situatie. Nog afgezien van de vraag waar deze term nu eigenlijk precies voor staat (gelet op de verschillende betekenissen die daaraan worden toegekend door vooral politici), is het niet meer dan een politiek-ideologische kreet. Om nu te veronderstellen dat daarmee de huidige samenleving ook valt te kenschetsen als een participatiemaatschappij, is niet alleen 
naïef, maar gaat ook voorbij aan de conflicten die er bestaan over de betekenis en doelen van participatie en non-participatie.

Tot slot, in het verlengde van de vraag van Zedner (2003) of er te veel veiligheidszorg kan zijn, kan de vraag worden gesteld of er ook een te veel aan burgerparticipatie in de veiligheidszorg kan zijn. In tegenstelling tot wat de term participatiemaatschappij lijkt te impliceren, moet die vraag bevestigend worden beantwoord. Deels hangt dat samen met het feit dat burgerparticipatie ook negatieve gevolgen kan hebben, zoals sociale uitsluiting van bepaalde groepen en personen, en kan bijdragen aan angst onder burgers voor uiteenlopende verschijnselen en aan de neiging zich voor elkaar af te sluiten. Burgerparticipatie in de veiligheidszorg kan bovendien, zoals met enkele voorbeelden in deze bijdrage duidelijk is geworden, bijdragen aan de tegenstellingen in de samenleving en de centrale waarden van rechtsstaat en democratische samenleving ondermijnen. Om die reden opperde Crawford al in 1997 dat de aanpak van criminaliteit niet de beste basis is om open, tolerante en inclusieve samenlevingen te creëren. De vraag is dan ook of het mobiliseren van burgers op basis van veiligheid de tegenstellingen en conflicten in de samenleving niet juist zal versterken (Terpstra \& Kouwenhoven 2004, p. 286-288). De vraag naar de grenzen van deze burgerparticipatie wint daarnaast aan urgentie nu deze burgerparticipatie deels lijkt te worden overgenomen door groepen die doelbewust uit zijn op het verminderen van gastvrijheid, medemenselijkheid en tolerantie onder het motto van het belang van veiligheid.

\section{Literatuur}

\section{Bennett e.a. 2006}

T. Bennett, K. Holloway \& D.P. Farrington, 'Does neighborhood watch reduce crime? A systematic review and meta-analysis', Journal of Experimental Crimino$\operatorname{logy}(2)$ 2006, afl. 4, p. 437-458.

\section{Boutellier 2007}

J.C.J. Boutellier, Nodale orde. Veiligheid en burgerschap in een netwerksamenleving (oratie Amsterdam VU), 2007.

\section{Crawford 1997}

A. Crawford, The local governance of crime: Appeals to community and partnerships, Oxford: Oxford University Press 1997. 
88 Justitiële verkenningen, jrg. 42, nr. 5, 2016

\section{De Haan 1995}

W.J.M. de Haan, 'Integrale veiligheid. Beleidsvernieuwing of beleidsvervaging?', Justitiële verkenningen (21) 1995, afl. 5, p. 25-48.

\section{Pawson \& Tilley 1997}

R. Pawson \& N. Tilley, Realistic evaluation, Londen: Sage 1997.

\section{Sherman e.a. 1997}

L.W. Sherman, D.C. Gottfredson, D.L. MacKenzie, J. Eck, P. Reuter e.a. (red.), Preventing crime:

What works, what doesn't, what's promising (Report to the U.S. Congress), Washington, DC: US Office of Justice Programs 1997.

\section{Terpstra 2010}

J. Terpstra, Het veiligheidscomplex. Ontwikkelingen, strategieën en verantwoordelijkheden in de veiligheidszorg, Den Haag: Boom Juridische uitgevers 2010.

\section{Terpstra \& Kouwenhoven 2004}

J. Terpstra \& R. Kouwenhoven, Samenwerking en netwerken in de lokale veiligheidszorg, Apeldoorn/Enschede: CP\&W/IPIT 2004.

\section{Zedner 2003}

L. Zedner, 'Too much security?', International Journal of the Sociology of Law (31) 2003, afl. 3, p. 135-184. 